\title{
Suspected ovarian molar pregnancy after assisted reproductive technology conception: a diagnostic challenge
}

\author{
Nedaa Obeidi, ${ }^{1}$ Nairi Tchrakian, ${ }^{2}$ Feras Abu Saadeh, ${ }^{3}$ Edgar Mocanu ${ }^{4}$
}

${ }^{1}$ Human Assisted Reproduction Ireland, Dublin, Ireland ${ }^{2}$ Department of

Histopathology, Rotunda Hospital, Dublin, Ireland

${ }^{3}$ St. James's Hospital, Dublin, Ireland

${ }^{4}$ Royal College of Surgeons, Ireland

\section{Correspondence to}

Dr Feras Abu Saadeh,

ferasabusaadeh@dubgyn.org

Accepted 26 February 2015

\section{SUMMARY}

A 32-year-old patient with primary infertility received in vitro fertilisation (IVF) therapy. Four weeks later she developed intermittent left iliac fossa pain. Transvaginal ultrasound showed an empty uterus and an adnexal mass adjacent to the right ovary. Serum $\beta$-human chronic gonadotropin was 33492 IU/L. At laparoscopy a mass attached to right ovary, suggestive of a right ovarian ectopic pregnancy, was excised. Histological examination confirmed an ovarian ectopic gestation, but noted enlarged chorionic villi and trophoblastic atypia, which raised the suspicion of molar pregnancy. Subsequent p57 immunohistochemistry and DNA ploidy studies excluded a mole, however. Cases of suspected molar disease in ectopic pregnancy present a diagnostic challenge for both clinicians and histopathologists, and establishing a definitive diagnosis may be difficult.

\section{BACKGROUND}

Ectopic gestational trophoblastic disease is rare. Affected patients usually present with symptoms of conventional ectopic pregnancy, and the diagnosis of hydatidiform mole is subsequently made based on the histological examination of the surgical specimen. Despite its rare occurrence, ectopic molar pregnancy is often over-diagnosed, a problem that is highlighted in a 2005 study by Sebire et al. ${ }^{1}$

\section{CASE PRESENTATION}

A 32-year-old nulliparous lady with a background of primary infertility and previous laparoscopic left microsurgical salpingostomy for hydrosalpinx attended for in vitro fertilisation (IVF). She received an antagonist protocol utilising Puregon $150 \mathrm{IU}$ for ovarian stimulation. After 11 days of stimulation, 15 eggs were collected transvaginally and a single day 5 embryo was transferred under ultrasound (US) guidance.

The patient presented 10 days post embryo transfer with left iliac fossa (LIF) pain and vaginal bleeding of one day's duration. Clinical examination was unremarkable. A pelvic US showed an empty uterus, ovaries of normal size and a small amount of free fluid in the pouch of Douglas (POD). Serum human chorionic gonadotropin ( $\beta$-hCG) was $5 \mathrm{IU} / \mathrm{L}$, and she was managed conservatively.

She was reviewed 2 days later when symptoms had resolved. One month later, the patient presented with intermittent LIF pain and a positive urine pregnancy test. On examination she was haemodynamically stable, and the abdomen was soft and lax, with

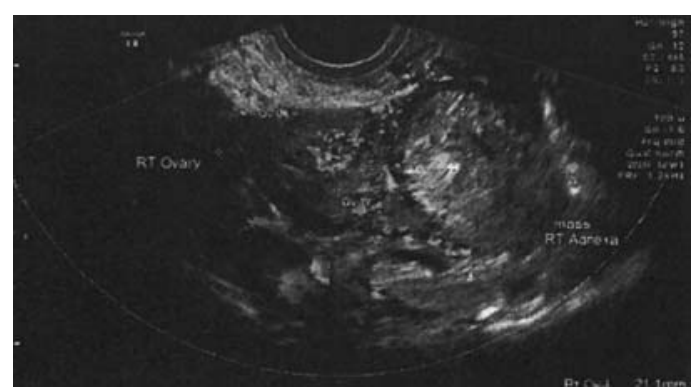

Figure 1 Pelvic ultrasound showing an enlarged right ovary and free fluid in the pelvis, suggestive of ectopic pregnancy.

no tenderness or guarding. Cervical excitation was not present.

\section{INVESTIGATIONS}

Pelvic US revealed a $36 \times 34 \mathrm{~mm}$ mass in the right adnexa, adjacent to the right ovary (figure 1). A significant amount of free fluid of low echogenicity was identified in the POD, suggestive of haemoperitoneum. No intrauterine pregnancy was identified. Serum $\beta$-hCG was 33492 IU/L. Serial haemoglobin levels showed a drop from 13.9 to $11.3 \mathrm{~g} / \mathrm{dL}$.

\section{DIFFERENTIAL DIAGNOSIS}

- Ectopic pregnancy

- Ectopic gestational trophoblastic disease

- Heterotopic pregnancy

- Theca lutein cyst

\section{TREATMENT}

Diagnostic laparoscopy was performed. A significant amount of blood was present in the pelvis.

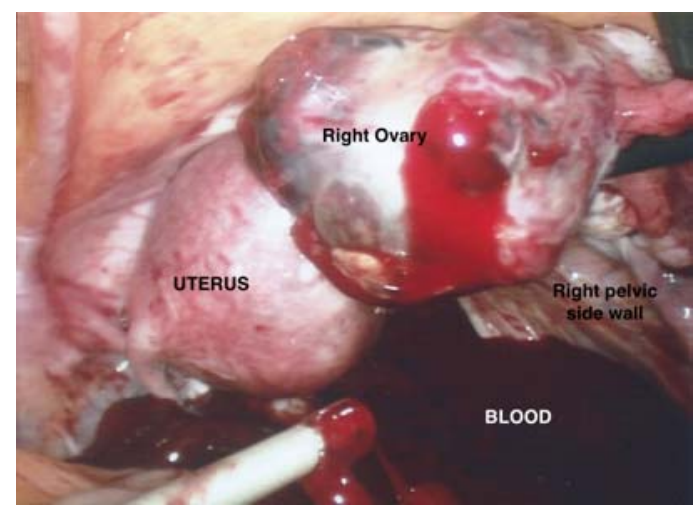

Figure 2 Laparoscopic picture of the pelvis with haemoperitoneum and an enlarged and abnormal right ovary. 

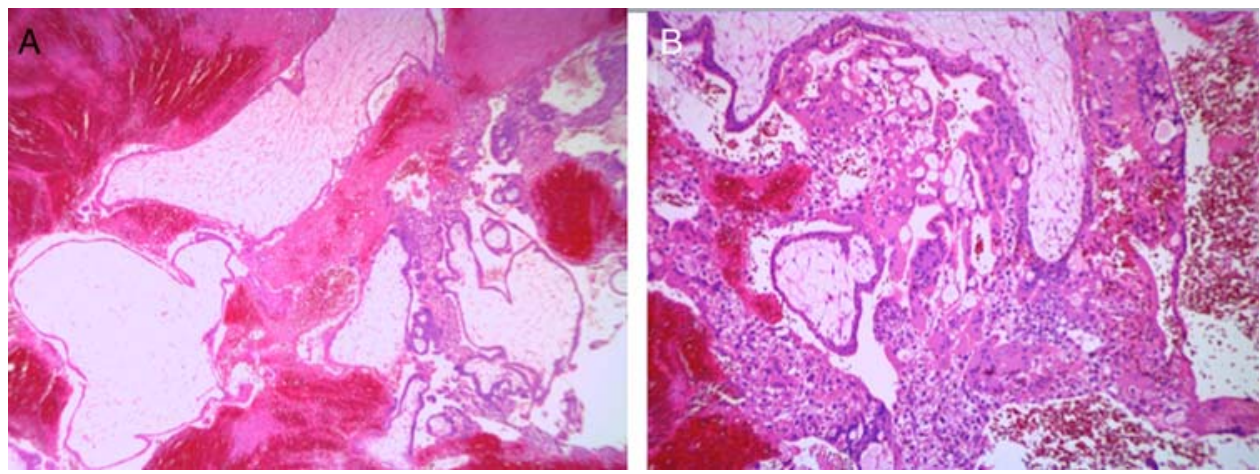

Figure 3 H\&E slide showing (A) Variably-sized chorionic villi with some hydropic forms (B) Foci of trophoblast hyperplasia.

The uterus and left ovary appeared normal, and the left tube was normal, aside from a Prolene suture, present from previous surgery. A mass was noted on the right ovary, suggestive of ovarian ectopic pregnancy (figure 2). A laparoscopic partial oophorectomy was performed and the specimen was sent for histological examination. The patient had an uneventful recovery postoperatively and was discharged home the next day.

\section{OUTCOME AND FOLLOW-UP}

Histological examination of the right partial oophorectomy specimen showed chorionic villi, pregnancy decidua and infiltrating trophoblast, in keeping with the clinical impression of an ovarian ectopic gestation. However, variability of the size of the chorionic villi was noted, with some larger, hydropic, forms present. In addition, foci of trophoblastic proliferation were identified. These morphological features were considered suspicious for, but not diagnostic of molar pregnancy (figure 3). Long-term patient follow-up with serial $\beta$-hCG monitoring was performed at weekly intervals until the level dropped to below $2 \mathrm{IU} / \mathrm{L}$, and then at monthly intervals for 3 months thereafter. Meanwhile, a p57 immunostain was performed; this showed positivity in villous mesenchyme and cytotrophoblast, thereby excluding the diagnosis of complete mole (figure 4). In addition, DNA ploidy analysis by fluorescent in vitro hybridisation (FISH) revealed a diploid chromosomal complement. This excluded the diagnosis of a partial molar pregnancy, which typically has a triploid genome. The combined morphological, immunohistochemical and cytogenetic features indicated a non-molar hydropic ectopic pregnancy.

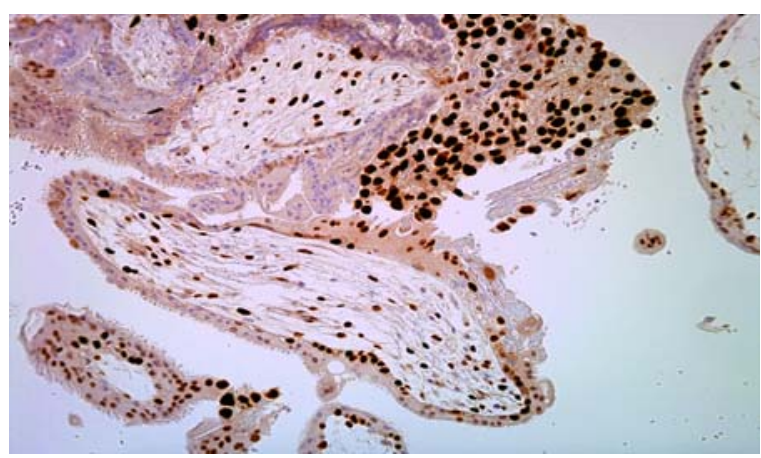

Figure 4 Positive p57 staining in villous mesenchyme and cytotrophoblast. This staining pattern excludes complete mole, but cannot distinguish between a hydropic abortion and a partial mole.

\section{DISCUSSION}

The incidence of ectopic pregnancy is $1-2$ per 100 pregnancies, with an ovarian site representing $1-3 \%$ of these. Factors that increase the incidence of ovarian pregnancy are younger age, endometriosis, pelvic inflammatory disease, intrauterine devices, use of ovulatory medications and assisted reproduction techniques. Ectopic molar gestation is very rare; the incidence is estimated to be only 1.5 per million births. ${ }^{2}{ }^{3}$

To the best of our knowledge, only 14 cases of ovarian ectopic gestation have been reported from 1925 to date.

Patients with ovarian molar pregnancy present with symptoms of ectopic pregnancy rather than typical features of molar pregnancy. While a suspicion of molar disease can be raised following detection of high serum $\beta$-hCG, diagnosis is typically based on histopathological examination of the excised specimen. However, the histological evaluation of molar pregnancy can be difficult in cases of ectopic gestation, as the degree of trophoblast proliferation is often more florid in ectopic gestations when compared with the more commonly encountered evacuated uterine products of conception. Given the challenging nature of these cases and the consequent risk of over-diagnosis of molar pregnancy, ancillary testing such as immunohistochemistry for p57 and ploidy analysis may be required in order to definitively confirm or refute the diagnosis.

A 2005 paper from a UK Trophoblastic Disease Centre highlights the problem of over-diagnosing hydatidiform mole in ectopic pregnancies. Here, cases with a referral diagnosis of tubal hydatidiform mole were subject to expert review, and the diagnosis was confirmed in only $6 \%$ of the cases. ${ }^{1}$ In our case, three expert pathologists reviewed the histological specimen, and raised the possibility of molar pregnancy based on certain

\section{Learning points}

- Ovarian ectopic gestation is a rare occurrence, and ovarian molar gestation is exceptional.

- The clinical and intraoperative diagnosis is usually difficult, and histological examination of the surgical specimen is the gold-standard for definitive diagnosis.

- The morphological appearances are not always sufficient to make a definitive histological diagnosis of ovarian molar pregnancy, and ancillary techniques may be helpful.

- When in doubt, a second opinion on the histological specimen should be sought.

- A multidisciplinary approach towards diagnosis and follow-up is recommended. 
morphological features, described above. However, molar pregnancy was ultimately excluded by the results of immunohistochemistry and ploidy studies. This outcome was unsurprising, given the rarity of ectopic molar disease.

Competing interests None.

Patient consent Obtained.

Provenance and peer review Not commissioned; externally peer reviewed.

\section{REFERENCES}

1 Sebire NJ, Lindsay I, Fisher RA, et al. Overdiagnosis of complete and partial hydatidiform mole in tubal ectopic pregnancies. Int I Gynecol Pathol 2005;24: 260-4.

2 Church E, Hanna L, New F, et al. Ovarian molar pregnancy. J Obstet Gynaecol 2008;28:660-1.

3 Suzuki H, Matsubara S, Uchida S, et al. Ovary hyperstimulation syndrome accompanying molar pregnancy: case report and review of the literature. Arch Gynecol Obstet 2014;290:803-6.

Copyright 2015 BMJ Publishing Group. All rights reserved. For permission to reuse any of this content visit http://group.bmj.com/group/rights-licensing/permissions.

BMJ Case Report Fellows may re-use this article for personal use and teaching without any further permission.

Become a Fellow of BMJ Case Reports today and you can:

- Submit as many cases as you like

- Enjoy fast sympathetic peer review and rapid publication of accepted articles

- Access all the published articles

- Re-use any of the published material for personal use and teaching without further permission

For information on Institutional Fellowships contact consortiasales@bmjgroup.com

Visit casereports.bmj.com for more articles like this and to become a Fellow 